\title{
Fixed Human Resource Norms in Indian Sub Centers - Does the Changing Times Necessitate Innovations?
}

\author{
Suchitra Lisam, Dilip Singh Mairembam, Anupama Hazarika, Prankul Goel, Roli Srivastava and Thiagarajan \\ Sundararaman
}

\begin{abstract}
This study was conducted to understand the existing workforce availability and need for differential staffing norms within diverse contexts of sub centers (SCs). This included documenting the emerging patterns of SCs, studying the existing staffing norms, and assessing the ranges, quantum of services, work-pattern and work-load of service providers. Multiple case studies were used to document the diverse contexts of SCs along with review of secondary data. In-depth interviews of 97 service providers including Auxiliary Nurse Midwives (ANM), Multi-purpose Worker Male (MPW$M)$ and Rural Health Practitioners (RHP) was conducted to assess the characteristics, work-pattern and work-load across 69 sub-centers in Haryana, Chhattisgarh, Kerala, Assam, Rajasthan, Uttar Pradesh (U.P) and Meghalaya. SCs across these states were differentiated into various types i.e. collocated in Primary Health Centers (PHC) or standalone, delivery huts or non-delivery huts and Non-Communicable Diseases (NCD) clinics. While SCs in most states were providing minor symptomatic treatment, Antenatal Care $(A N C)$, immunization services through outreach work, in few states, the focus had shifted from Maternal \& Child Health Care services to detection of NCDs and adolescent health. This study found inter- and intra- state variations on workload, work pattern, staff deployment, Out Patient Department (OPD) attendance and areas of work of the staff deployed in SCs. Similarities and variations on workload and work pattern across SCs were observed across the state. Majority of SCs showed variations in terms of average number of villages, population served and geographical contexts across states. Assam SCs had heavy OPD attendance of upto
\end{abstract}

Suchitra Lisam, Senior Consultant, Human Resources for Health, National Health Systems Resource Center, New Delhi, India. E-mail: drsuchitra.nhsrc@gmail.com

Dilip Singh Mairembam, Advisor, Human Resources for Health, National Health Systems Resource Center, New Delhi, India. E-mail: drdilipsingh@gmail.com

Anupama Hazarika, Senior Consultant, Policy and Coordination, National Health Systems Resource Center, New Delhi, India. E-mail: hazarikaa@gmail.com

Prankul Goel, Consultant, Human Resources for Health, National Health Systems Resource Center, New Delhi, India. E-mail: prankulg12002@yahoo.com

Roli Srivastava, Senior Program Manager, MAMTA Health Institute of Mother \& Child, New Delhi.E-mail: drroli.nhsrc@gmail.com

Thiagarajan Sundararaman, Executive Director, National Health Systems Resource Center, New Delhi, India. E-mail: sundararaman.t@gmail.com
33 cases per day due to deployment of an additional mid level health worker in the form of RHPs while other states (i.e. Haryana, Chhattisgarh and U.P) had relatively low OPD attendance of upto 5 cases per day. While the Indian Public Health Standards (IPHS) prescribed 2 ANMs and $1 \mathrm{MPW}(\mathrm{M})$ at each SC, the study found that 37 SCs (53.6 percent) had only 1 staff in place as observed in 6 states except in Assam where 8 SCs had 1 RHP at each SC along with either 1 or 2 ANMs, out of total 15 SCs studied. Staffing pattern at SC did not consider the geographical, social and work characteristics of SC. Our study findings demonstrates that flexible staffing norms is necessary which should be based not only on caseloads, but certain factors i.e. population served, emerging characteristics of the SC and geographical accessibility should be considered for rational deployment of ANMs at SCS. Besides, skill building of staffs, deployment of secondth ANM and an additional health worker i.e. RHP are crucial for optimal delivery of assured services at SCs. It could be complemented by adoption of locally appropriate retention strategies for staffs.

Keywords--- Auxiliary Nurse Midwives, Indian Public Health Standards, Multi-Purpose Worker (Male), Rural Health Practitioners

\section{INTRODUCTION}

$\mathrm{T}$ HE emphasis of primary health care in India has been on universal access; especially for the rural poor and national program planning has been subjected to modifications based on local conditions, needs and circumstances [1]. The Alma Ata Declaration advocated the provision of first contact services and basic medical care within the framework of an integrated health services. [2].

The Mudaliar Committee, in 1961, was the first to conceive the idea of having three grades of nurses including Auxiliary Nurse Midwives (ANM) as well as male and female health workers or Multi Purpose Worker (MPW) at grass root level for serving a population of 3000-3500 [3]. Currently, under the Indian Public Health Standard (IPHS) norms, each sub-center has to be staffed by one ANM/ Female Health Worker and one Male Health Worker. Under the National Rural Health Mission (NRHM), there is a provision for one additional second ANM on contract basis. 
A Sub Center (SC) is the most peripheral and first contact point between primary health care systems and community. [4]. SCs are assigned tasks to provide basic maternal and child health services, family welfare, nutrition, immunization, diarrhea control and control of communicable disease programmes [5], [6]. Constraints in optimal utilization of these services are due to the geographical diversity and wide dispersion in population within the hamlets served by these SCs [6]. Significant shortage of human resources was observed especially when taken in relation to, topography, job responsibilities and prevalence of several factors that seriously affected performance of SCs. [7]. Better communication and advocacy between the Village Health and Sanitation Committees (VHSC) and the Local Block Level Health and Administrative Officers lead to better service utilization by the local population, resulting in improved health outcomes [8].

\section{A. Study Rationale}

The nature of SCs has been changing rapidly within and across the states. SCs are no longer sites for normal delivery of the pregnant woman in Kerala, Punjab, Chandigarh and Nagaland. A significant portion of immunization services and ante-natal care are being provided in Primary Health Centers (PHC) in Tamil Nadu. To fill this vacuum in workload, these states have introduced programmatic interventions in areas of non - communicable diseases (NCDs) and adolescent's health. In other states also, SCs has been reduced to an outreach center for providing immunization and antenatal care without any midwifery function [9].

\section{B. Study Objectives}

In this context, the study was conducted to understand the need for flexible staffing norms within diverse context with the following objectives:

- Document the emerging patterns of sub-centers

- Study the existing staffing norms

- Assess the range \& quantum of services

- Work-pattern and work-load of service providers

\section{StUdy Design AND Methods}

Mixed methods were used with quantitative and qualitative components. Qualitative research based on multiple case studies was used to examine the existing service delivery patterns and facilitate exploration of variation within different contexts of SCs. Multiple case studies and desk reviews were used to document the diverse contexts of SCs, available workforce and existing practices.

\section{A. Secondary Data Review}

Secondary data from NRHM Routine Health Management Information System (HMIS) was analyzed to explore and understand the multiple facets of SCs namely human resource deployment, infrastructure, population served and services delivered. HMIS data of 1-year period (August 2010 to July 2011) was studied with regard to Reproductive Child Health $(\mathrm{RCH})$ performance, general Out Patient Department (OPD) and laboratory services to see if there was any relation between performance, population served and staffing.

\section{B. Primary Data Collection}

In-depth interview of service providers was conducted using semi-structured questionnaire to gain insight on work pattern, workload and functionality of SCs.

\section{Study Sample}

Purposive sampling method was used for selection of samples at different levels - states, districts, blocks and subcenters. Seven states were selected from five regions viz. north, west, east, south and northeast with representation of Empowered Action Group (EAG) and non-EAG states.

Districts, blocks and SCs were selected on the basis of fourteen (14) identified contexts and key RCH performance indicators (including Antenatal Care load, institutional deliveries, and immunization load) in 6 states and delivery of NCD screening services in Kerala. The 14 contexts chosen in 7 states were near urban, remote area of Haryana, tribal, urban and agricultural areas of Chhattisgarh, urban, median and riverine areas of Assam, semi-urban area of Kerala, densely population, desert area of Rajasthan, Bundelkhand area of Uttar Pradesh (U.P) and remote hilly area, near urban hilly area of Meghalaya. (ref: Table I)

Besides, location (remote and urban) of SC, geographical accessibility and availability of staff at SC were also considered.

Table I: State wise List of Average Performing Districts

(Source: NRHM- Health Information Management System, HMIS; Sep 2010 to August 2011)

\begin{tabular}{|c|c|c|c|c|c|}
\hline \multirow[t]{2}{*}{ State } & \multirow[t]{2}{*}{ Context (district) selected } & \multicolumn{4}{|c|}{ Performance Indicators of district (Sep'10- Aug'11) } \\
\hline & & $\begin{array}{l}\% \text { Pregnant women } \\
\text { with } 3 \text { ANC check } \\
\text { up against estimated } \\
\text { pregnancies (points) }\end{array}$ & $\begin{array}{c}\% \text { Immunized } \\
\text { children less than } \\
1 \text { yr. against } \\
\text { estimated live } \\
\text { births (points) }\end{array}$ & $\begin{array}{c}\% \text { Institutional } \\
\text { deliveries against } \\
\text { estimated } \\
\text { deliveries (points) }\end{array}$ & $\begin{array}{l}\text { Total } \\
\text { Points }\end{array}$ \\
\hline Haryana & Near Urban, remote area (Karnal) & $63 \%(2)$ & $86 \%(3)$ & $85 \%(3)$ & 8 \\
\hline Chhattisgarh & $\begin{array}{l}\text { Tribal/forest, urban and } \\
\text { agricultural areas (Raipur) }\end{array}$ & $46 \%(1)$ & $52 \%(1)$ & $53 \%(2)$ & 4 \\
\hline \multirow{3}{*}{ Assam } & Urban (Kamrup), & $54 \%(1)$ & $40 \%(2)$ & $76 \%(2)$ & 6 \\
\hline & Median (Kokrajhar), & $63 \%(2)$ & $84 \%(3)$ & $59 \%(2)$ & 7 \\
\hline & Riverine areas (Hailakandi) & $75 \%(2)$ & $103 \%(3)$ & $47 \%(2)$ & 7 \\
\hline
\end{tabular}




\begin{tabular}{|c|c|c|c|c|c|}
\hline Kerala & $\begin{array}{l}\text { Semi-urban area having high } \\
\text { OPD load/NCD focus, } \\
\text { (Pathanamthitta) }\end{array}$ & $24 \%(1)$ & $32 \%(1)$ & $28 \%(1)$ & 3 \\
\hline \multirow{2}{*}{ Rajasthan } & Densely populated (Jaipur), & $61 \%(2)$ & $69 \%(2)$ & $76 \%(3)$ & 7 \\
\hline & Desert (Bikaner) & $72 \%(2)$ & $101 \%(3)$ & $56 \%(2)$ & 7 \\
\hline \multirow[t]{2}{*}{ Uttar Pradesh } & Bundelkhand area (Jhansi) & $54 \%(1)$ & $74 \%(2)$ & $42 \%(2)$ & 5 \\
\hline & Remote hilly (East Khasi Hills) & $81 \%(3)$ & $60 \%(3)$ & $81 \%(3)$ & 9 \\
\hline \multirow[t]{2}{*}{ Meghalaya } & Remote hilly (Jiantia Hills) & $52 \%(1)$ & $100 \%(3)$ & $54 \%(2)$ & 6 \\
\hline & Near Urban hilly (Ribhoi) & $67 \%(2)$ & $82 \%(3)$ & $18 \%(1)$ & 6 \\
\hline
\end{tabular}

Primary data of interviews was segregated thematically and analyzed to gain insights on work pattern of respondents, functionality of SCs in the last 7 days including the day of interview. Sample of SCs were drawn to have uniform representations as described in Table 1 . In-depth interviews of

Table II: Distribution of Sample Size Across 7 States

\begin{tabular}{|c|c|c|c|c|c|c|}
\hline State & & Districts & $\begin{array}{l}\text { No. of sub } \\
\text { centers }\end{array}$ & $\begin{array}{l}\text { No. of ANM } \\
\text { interviewed }\end{array}$ & $\begin{array}{l}\text { No. of MPW } \\
\text { (M) interviewed }\end{array}$ & $\begin{array}{l}\text { No. of RHP } \\
\text { interviewed }\end{array}$ \\
\hline Rajasthan & & 2 & 10 & 13 & 0 & 0 \\
\hline Haryana & & 1 & 10 & 12 & 0 & 0 \\
\hline Chhattisgarh & & 1 & 15 & 15 & 0 & 0 \\
\hline Uttar Pradesh & & 1 & 6 & 6 & 1 & 0 \\
\hline Assam & & 3 & 15 & 24 & 5 & 7 \\
\hline Meghalaya & & 3 & 8 & 7 & 0 & 0 \\
\hline Kerala & & 1 & 5 & 5 & 0 & 0 \\
\hline & Total & 12 & 69 & 84 & 6 & 7 \\
\hline
\end{tabular}

\section{STUDY RESULTS}

In 1946, the Bhore Committee Report [1], envisaged establishment of sub-centers (SC) for a population of 5000 in plains and 3000 in difficult areas (tribal, hilly and desert areas). This was reiterated by the Bajaj Committee Report of 1986 [4] , in the present context of health care service delivery. Yet there still exists a gap in the required and existing sub centers. As of March, 2010 there are 1, 47,069 SCs functioning with an average coverage of 5049 rural population as against a requirements of $1,58,792$ SCs thus reiterating the fact that are many underserved areas across the country.

\section{A. Deviations from Bhore and Bajaj Committee Recommendations for SCs for Population served}

The study findings showed that there are variations across the SCs in various states in terms of average number of villages and population served by each SC. Out of 69 SCs taken up for the study, 24 of them served a population of more than 5,000. (ref: Table III). T he study reveals that out of 13 contexts chosen in 7 states, SCs located in median area of Assam served an average number of 10 villages, while the SCs in desert area of Rajasthan served an average of 1 village (SCs in near urban areas of Haryana served an average 7661 population (maximum) while SCs in tribal areas of Chhattisgarh served an average of 2543 population (minimum).
97 service providers i.e. $84(87 \%)$ ANM, $6(6 \%)$ MPW/Health Worker (HW) and 7 (7.2\%) Rural Health Practitioners (RHP) was conducted across 12 districts in 69 sub-centers of 7 states. (ref: Table II) 
geographical contexts (tribal, agricultural, near urban) had only one ANM though institutional deliveries took place in 11 of them.(ref: Table III)

The NRHM has a provision of a secondth ANM [11], with priority at SCs conducting institutional deliveries. Since the inception of the NRHM, 60,268 ANMs (as on $31^{\text {st }}$ March, 2011) have been recruited on contractual basis. But the study proves that rational deployment still remains an issue as 24 of the 35 SCs $(68.5 \%)$ where deliveries took place have been staffed with only one ANM (ref: Table III)

Table III: Service Delivery at Sub Center

(Source: Secondary Data of Sub-centers, district report; August, 2010 to July, 2011)

\begin{tabular}{|c|c|c|c|c|c|c|c|c|c|}
\hline \multirow{2}{*}{$\begin{array}{l}\text { Name of } \\
\text { state }\end{array}$} & \multirow{2}{*}{$\begin{array}{l}\text { Name of Sub- } \\
\text { center }\end{array}$} & \multirow{2}{*}{$\begin{array}{c}\begin{array}{c}\text { Popul } \\
\text { ation }\end{array} \\
\end{array}$} & \multirow{2}{*}{$\begin{array}{l}\text { No. } \\
\text { of } \\
\text { staff }\end{array}$} & \multicolumn{6}{|c|}{ SC performance indicators (Aug'10-July'11) } \\
\hline & & & & OPD & $\begin{array}{l}3 \\
\mathrm{AN} \\
\mathrm{C}\end{array}$ & $\begin{array}{c}\text { Institutional } \\
\text { deliveries }\end{array}$ & $\begin{array}{l}\text { Fully immunized } \\
<1 \mathrm{yr}\end{array}$ & $\begin{array}{l}\text { No. of } \mathrm{Hb} \\
\text { tests done }\end{array}$ & $\begin{array}{c}\text { Malaria slides } \\
\text { collected/100 } \\
\text { pop }\end{array}$ \\
\hline \multirow{10}{*}{ Haryana } & Nigdhu & 9260 & 1 & 772 & 225 & 167 & 199 & 184 & 315 \\
\hline & Uplana & 6931 & 2 & 337 & 159 & 106 & 198 & 212 & 602 \\
\hline & Raison & 9348 & 1 & 779 & 112 & 134 & NA & 148 & 799 \\
\hline & Ror-majra & 7831 & 1 & 1570 & 84 & 172 & 184 & 112 & 87 \\
\hline & Thal & 4939 & 1 & 337 & 46 & 8 & 25 & 56 & 5 \\
\hline & Gheer & 8896 & 2 & 862 & 160 & NA & 187 & 243 & 663 \\
\hline & Shamgarh & 8500 & 2 & 638 & 127 & 88 & 43 & 174 & 501 \\
\hline & Newal & 9038 & 2 & 375 & 260 & 191 & 212 & 0 & 174 \\
\hline & Pathana & 6015 & 2 & 510 & 20 & 103 & 101 & 0 & 625 \\
\hline & Shahpur & 3598 & 2 & 579 & 63 & 66 & 0 & 138 & 506 \\
\hline \multirow{15}{*}{$\begin{array}{c}\text { Chhattisgar } \\
\text { h }\end{array}$} & Gohrapad & 2309 & 1 & 1571 & 52 & 56 & 76 & 79 & 185 \\
\hline & Bardula & 2954 & 1 & 2038 & 88 & 68 & 72 & 87 & 479 \\
\hline & Gaurgaon & 2145 & 1 & 1736 & 50 & 35 & 56 & 50 & 321 \\
\hline & Indragaon & 2675 & 1 & 1803 & 50 & 60 & 48 & 87 & 253 \\
\hline & Subha & 2634 & 1 & 2021 & 81 & 21 & 57 & 80 & 412 \\
\hline & Kirwai & 3285 & 1 & 317 & NA & NA & 0 & 0 & 304 \\
\hline & Puraina & 3130 & 1 & 383 & 42 & 22 & 59 & 68 & 340 \\
\hline & Pasaud & 3000 & 1 & 367 & 62 & 41 & 71 & 45 & 425 \\
\hline & Charauda & 4380 & 1 & 573 & 104 & 29 & 100 & 19 & 420 \\
\hline & Shyamnagar & 2810 & 1 & 138 & 53 & 23 & 48 & 0 & 321 \\
\hline & Kendri & 5505 & 1 & 0 & 98 & 44 & 107 & 0 & 460 \\
\hline & Kolar & 5933 & 1 & 1102 & 64 & 2 & 163 & 119 & 1726 \\
\hline & Khorpa & 6182 & 1 & 403 & 20 & 0 & 0 & 141 & 1064 \\
\hline & Sarkhi & 4336 & 1 & 0 & 0 & 0 & 76 & 118 & 604 \\
\hline & Urla & 5787 & 2 & 312 & 84 & 0 & 153 & 155 & 745 \\
\hline \multirow{10}{*}{ Rajasthan } & Dudiwali & 1500 & 2 & 470 & 20 & 20 & 27 & 72 & 33 \\
\hline & Khiyera & 3305 & 1 & 2442 & 82 & 137 & 90 & 207 & 18 \\
\hline & Dava & 3170 & 1 & 522 & 59 & 135 & 127 & 137 & 12 \\
\hline & Ghadwala & 5363 & 2 & 767 & 141 & 27 & 164 & 157 & 13 \\
\hline & Surdhana & 2204 & 1 & 1391 & 31 & 0 & 39 & 103 & 11 \\
\hline & Udaipuria & 7717 & 1 & 1724 & 119 & 164 & 146 & 373 & 10 \\
\hline & Kukas & 4800 & 1 & 1583 & 56 & 320 & 71 & 103 & 6 \\
\hline & Mohana & 3170 & 2 & 853 & 55 & 0 & 338 & 0 & 19 \\
\hline & Thali & 6500 & 1 & 1371 & 105 & 44 & 59 & 72 & 0 \\
\hline & Karedakhurd & 6000 & 1 & 760 & 28 & 0 & 84 & 0 & 0 \\
\hline \multirow{6}{*}{$\begin{array}{l}\text { Uttar } \\
\text { Pradesh }\end{array}$} & Baghera & 3700 & 1 & 659 & 113 & 1026 & 7 & 0 & 0 \\
\hline & Bangra & 6000 & 1 & NA & NA & NA & NA & NA & NA \\
\hline & Jiryai & 3500 & 1 & 51 & 44 & 478 & 49 & 0 & 0 \\
\hline & Ghughwa & 5000 & 1 & NA & NA & NA & NA & NA & NA \\
\hline & Jawan & 3034 & 1 & 72 & 3 & 18 & 42 & 0 & 0 \\
\hline & Sakrar & 9000 & 1 & 275 & 123 & 296 & 136 & 0 & 0 \\
\hline \multirow{5}{*}{ Kerala } & Melukara & 3845 & 2 & 0 & 37 & 0 & 65 & 0 & 0 \\
\hline & Thumpamon & 4135 & 2 & 0 & 0 & 0 & 0 & 0 & 0 \\
\hline & Pannivizha & 5011 & 2 & 393 & 44 & 0 & 63 & 10 & 393 \\
\hline & Parakode & 5008 & 2 & 0 & 0 & 0 & 0 & 0 & 0 \\
\hline & Chekulen & 4144 & 2 & 0 & 40 & 0 & 51 & 0 & 0 \\
\hline \multirow{4}{*}{ Assam } & Moirapur & 2943 & 3 & 738 & 52 & 0 & 52 & 77 & 63 \\
\hline & Sajanpara & 3392 & 3 & 834 & 41 & 0 & 42 & 73 & 15 \\
\hline & Owzari & 4742 & 4 & 0 & 71 & 89 & 0 & 0 & 186 \\
\hline & Chakrapani & 2834 & 4 & 1631 & 18 & 0 & 41 & 0 & 70 \\
\hline
\end{tabular}




\begin{tabular}{|c|c|c|c|c|c|c|c|c|c|}
\hline & Futuri & 4648 & 5 & 5650 & 76 & 7 & 102 & 0 & 0 \\
\hline & Kacharithal & 3795 & 3 & 6 & 80 & 0 & 109 & 0 & 1363 \\
\hline & Bangalpur & 2398 & 2 & 4507 & 38 & 0 & 52 & 0 & 463 \\
\hline & Gaglacherra & 5729 & 2 & 3446 & 94 & 0 & 127 & 0 & 520 \\
\hline & Lakhinagar & 4696 & 2 & 383 & 90 & 0 & 136 & 0 & 762 \\
\hline & Shamlagaon & 4689 & 2 & 697 & 36 & 0 & 75 & 0 & 482 \\
\hline & Abhyakuti & 8561 & 2 & 364 & 145 & 0 & 127 & 0 & 627 \\
\hline & Bhotgaon & 15033 & 3 & 267 & 305 & 50 & 303 & 0 & 1210 \\
\hline & Borobadha & 3633 & 2 & 13304 & 94 & 0 & 114 & 0 & 316 \\
\hline & Satyapur & 2517 & 4 & 430 & 0 & 0 & 0 & 0 & 0 \\
\hline & Srirampur & 8121 & 3 & 1365 & 24 & 0 & 170 & 0 & 0 \\
\hline \multirow{8}{*}{ Meghalaya } & Umlaper & NA & 2 & 133 & 0 & 0 & 20 & 0 & 0 \\
\hline & Shashniang & 3230 & 3 & 230 & 0 & 0 & 55 & 0 & 16 \\
\hline & Psir & NA & 2 & 240 & 0 & 0 & 87 & 0 & 16 \\
\hline & Thangrain & 2650 & 2 & 4006 & 48 & 0 & 31 & 0 & 244 \\
\hline & $\begin{array}{l}\text { Shilang } \\
\text { Myntang }\end{array}$ & 2537 & 1 & 5375 & 37 & 0 & 14 & 0 & 576 \\
\hline & Sonapur & NA & 2 & 2074 & 21 & 6 & 31 & 0 & 55 \\
\hline & Nohrun & 3106 & 1 & 716 & 14 & 0 & 20 & 0 & 0 \\
\hline & Wakhaliar & NA & 2 & 1434 & 8 & 0 & 55 & 16 & 0 \\
\hline
\end{tabular}

Although the IPHS norms define the ANMs' area of work in maternal and child health, family planning, adolescent health, school health programs and disease control programs among others, the SC functioned primarily as a site for treatment of minor ailments, ANC and immunization services with limited role in delivery of preventive and promotive health services, with few conducting deliveries.

\section{Work-Pattern and Work-Load at SCs}

This study reveals variations in work pattern and workload of institutional deliveries across states. While in Haryana, Chhattisgarh, institutional deliveries took place in majority of SCs, only a few SCs in Assam conducted deliveries. Majority of ANM in SCs of Rajasthan conducted deliveries ranging from 0-7 cases per week while in Haryana and Chhattisgarh, the range of delivery cases varies from 0-2 cases per week and 0-5 per week. (ref: Table III where maximum and minimum number of deliveries were used for calculating weekly ranges and are highlighted in bold)

We also noted variations in the patient OPD load of SCs across states. Average OPD load ranged from 1-112 cases per week, provided for 2-3 days per week. Majority of SCs in Assam showed very high OPD rates. ( ref: Table 3)

It was noted that all SCs provide symptomatic OPD and ANC services at the SC in the morning half on 3 days and conduct VHNDs once or twice a week. The afternoons are largely for household visits and paperwork. They also attend meetings at the PHC once or twice in a month.

\section{E. State specific Work pattern and Work-load}

\section{- Haryana Sub-Centers}

In Haryana, during a period of 7 working days, the ANM at a normative SC provided symptomatic OPD services from 9:00 AM to 13:00 PM on 3 days with an average load of 1-5 cases per week and provision of ANC services from 9:00 AM to 13:00 PM on 2 days. She attended one immunization session i.e. Village Health Sanitation Nutrition Committee (VHSNC) and visited 2 households for providing post-natal care and counseling services on another day. She conducted institutional delivery, 1 on each of the 3 days and documentation in one afternoon. Similar work pattern was observed in other sub-centers. Location and contexts of SCs and population served had no linkage with work-pattern or workload of ANM, except at 1 sub-center, where workload was higher than other SCs.

\section{- Rajasthan Sub-Centers}

In Rajasthan, the ANM in a normative SC had conducted 3 institutional deliveries in the last 1 week. She provided symptomatic OPD services on 4 days (9:00 AM to 13:00 PM) with an average daily load of 3-4 cases. She organized immunization sessions once a week on Thursday. She had mobilized 3 Post Natal Cases (PNC) to attend the family planning (FP) camps and did documentation on one afternoon (14:00-16:00 PM). She conducted home visits from 14:30 16:00 PM on 3 days for follow up of ANC/PNC, Tuberculosis (TB) patients and motivation for FP services. Similar work pattern of ANM was observed in other SCs where no institutional deliveries took place.

\section{- Chhattisgarh Sub-Centers}

Of the 15 SCs studied in Chhattisgarh, the ANM at Bardula SC provided OPD \& ANC services on 3 days with an average load of 2-3 cases per day. Immunization sessions were held during VHNDs twice a week (Tuesday, Friday) at Anganwadi Center (AWC). She conducted outreach work in afternoon on 3 days and attended the sector level meeting on Saturday. She spent 1-2 hours on documentation. While in the tribal/forest areas, SCs provided OPD services (3-5 cases/day) regularly on 4 days during the week. The ANM conducted field visits in the afternoon. VHND was held on every Tuesday for these SCs. In sub-centers in near urban area, the ANM had attended sterilization camps held once in a week either on Wednesday or Friday. The major role of collocated SCs was primarily outreach work.

\section{- Uttar Pradesh Sub-centers}

In Uttar Pradesh, SCs with residential facilities provided round-the-clock services. Two days in a week (Saturday and Wednesday) were scheduled for immunization session. In one of the sessions, the ANM had vaccinated 66 cases (vaccines 
i.e. Measles, Bacillus Calmette Guerin (BCG), Diptheria Pertussi Tetanus (DPT) 1 st, and DPT $2^{\text {nd }}$ ) and 2-3 cases of ANC. One day in a week (Tuesday) was fixed for staff meeting at PHC and preparation for VHND. OPD services were provided on 4 days. She had conducted 10 deliveries with an average of 2-3 cases per day in last week. She spent 23 hours per day on documentation. In one collocated sub center, OPD services were provided only on 1 day (Thursday).

\section{- Meghalaya Sub-Centers}

We also noted the emerging variation in workload and work pattern in Non-Government Organization (NGO) managed SC, under the Public Private Partnership (PPP) model. In Meghalaya, these NGO managed SCs also revealed that ANMs provided symptomatic OPD services on Friday with an average load of 10-15 cases per day. ANC services were provided during immunization services on Wednesday with an average load of 2-3 cases (both new ANC/follow up cases). She conducted home visits on 3 days i.e. Monday, Tuesday and Thursday where she provided ANC/PNC follow up, drop out cases, collection of malaria slides and blood samples

\section{- Kerala Sub-Centers}

With regard to variation in the focus of work area, Kerala is the only state that takes up health promotion and education activities for Adolescent Health as well as provision of NCD services. All $5 \mathrm{SCs}$ in Kerala located in semi-urban area focused on provision of NCD services and have common staffing pattern of 1 Junior Public Health Nurse (JPHN) / (ANM) and $1 \mathrm{MPW}$. The ANM provided ANC services on 2 consecutive days (Tuesday, Wednesday) with an average load of 1-2 cases per day. She organized School Health Program every Monday at school allocated to her. On Thursday, she attended NCD clinic for screening of Hypertension and Diabetes. She had conducted home visits on Tuesday and Wednesday for providing PNC/ANC follow up (2-3 cases). On Tuesday afternoon, she took health education classes for Anganwadi worker (AWW) at the SC and organized VHND at AWC on Thursday afternoon once a week.

\section{- Assam Sub-Centers}

In Assam, we noted a variation in the staffing pattern as well. SCs in the state have been upgraded with the addition of RHPs to improve range and quality of services. Value addition of MPWs can be seen as the laboratory services and collection of peripheral blood slides for malarial parasites had improved. The ANMs assisted the RHP in providing symptomatic OPD treatment and ANC services on 2 days (Tuesday, Friday) with an average OPD load of 20-30 cases per day and ANC load of 5-10 cases per day. On Tuesday, she distributed Mamoni/Majoni/Janani Surakshya Yojana( JSY)/Maternal \& Child Health (MCH) cheques to beneficiaries and conducted hemoglobin and urine tests at SC. On Wednesday, she organized VHND session and carried out Information Education \& Communication (IEC) activities. On Saturday, she assisted Mobile Medical Units (MMU) team in service delivery. On Tuesday and Friday afternoons, she did documentation and conducted outreach work on Thursday. The RHPs conducted institutional delivery at the sub-center and the regular ANM provided ANC and assisted RHP in OPD management while the contractual ANM conducted laboratory tests and follow up of cases (ANC/PNC) during home visits. The RHP provided OPD/ANC services on Monday, Tuesday, Wednesday, Thursday, Saturday with an average OPD load of 1-33 cases per day from 9:00 AM till 14:00 PM (ref: Table III)

\section{DISCUSSIONS}

States have posted health workers without taking into account the population served, geographical location, accessibility, service delivery or caseload. There is a need for flexible staffing norms that not only depends on caseloads but also other characteristics of sub-centers. Our study reveals that ANMs shared more or less similar kind of work-pattern. Majority of ANMs attend to 1-5 OPD including ANCs cases per day and outreach work are primarily limited to immunization sessions. In SCs with 2 ANMs, population coverage and field visits are divided between them. The maximum institutional delivery load at SCs designated as "delivery points" ranges from 3-5 per week, except in Chhattisgarh. In SCs with RHP, the ANM or MPW mainly assisted RHPs. MPW (M) usually performs laboratory tests. Documentation and record maintenance usually takes 3-4 hours in a week. ANMs are responsible for managing untied funds at SC and VHSC funds. Thus, the workload was determined not only by the location and population but also by the staffing pattern. While in Kerala, the work areas of ANMs have evolved to encompass NCDs and Adolescent Health along with routine activities.

\section{CONCLUSION}

The rational deployment of ANM/MPW would ensure that 2 ANMs or 1 ANM and 1 MPW (M) are made available in SCs covering larger population; difficult geographical locations covering dispersed population; SCs where institutional deliveries are taking place irrespective of whether they are designated delivery points and SCs with high case loads. MPWs play a key role in National Disease Control Programs (NDCP) and in malaria endemic areas. There is a felt need to revive the training institutions and syllabus to meet current public health challenges. The presence of RHPs in Assam has contributed towards enhanced performance of SCs reiterating the notion that an additional health worker such as RHP translates into higher footfalls provided the role of such workers is clearly defined. Hence, selection, training and deployment of an additional worker for complementing and improving services provided by ANM are crucial.

Sub-centers are also increasingly seen as the first port of call for screening of NCD. Trainings and capacity building of the existing health workers at SCs is necessary to handle these emerging disease profiles.

To be able to retain staff in underserved areas, localitybased "selection of candidates" or "post-training placement" is considered as an important indicator for retention of staff and states need to develop clear "transfer and posting policies" for the same. 


\section{ACKNOWLEDGEMENT}

The study was commissioned by the National Health Systems Resource Center (NHSRC), National Rural Health Mission (NRHM), Ministry of Health \& Family Welfare, Government of India and we would like to acknowledge the kind support and assistance provided by State Governments of Haryana, Rajasthan, Chhattisgarh, Uttar Pradesh, Kerala, Assam and Meghalaya.

\section{REFERENCE}

[1] J. Bhore, "Report of the Health Survey and Development Committee; Recommendations", Manager Of Publications, New Delhi, Vol. 2, 1946

[2] World Health Organization, "Alma Ata Declaration", International Conference on Primary Health Care, Alma Ata, USSR, 1978

[3] L. Mudaliar, "Report of the Health Survey and Planning Committee", Ministry of Health and Family Welfare, Government of Indi, New Delhi, Vol. 1. 1959-1961.

[4] Ministry of Health \& Family Welfare, "Rural Health Care System in India", Government of India, 2005

[5] Ministry of Health and Family Welfare, "Health manpower planning, production and development, Expert Committee (Bajaj,)", Ministry of Health \& Family Welfare, Government of India, New Delhi.

[6] K. Park, "Health Care Systems". Textbook of Preventive and Social Medicine 20th. Ed. Jabalpur, India: M/s Banarasidas Bhanot, 802 - 813.

[7] State Health Resource Centre, Strengthening Public Health Systems, “ Report of a Study on Issues of Workforce Management, Rationalization of Services and Human Resource Development in the Public Health Systems of Chhattisgarh State", SHRC Working papers 3,

[8] K. Mar, USAID, "Role of Village Health Committees in Improving Health and Nutrition Outcomes: A Review of Evidence from India", Evidence Review Series 4, The Vistaar Project, 2008

[9] Ministry of Health \& Family Welfare, National Rural Health Mission, Government of India, "Fourth Common Review Mission (CRM) Report 2010”, Pp. 5, 2011

[10] Government of India, "High Level Expert Committee Group Report on Universal Health Coverage for India", Planning Commission of India, Pp. 148, 2011.

[11] Government of India, Ministry of Health \& Family Welfare, "Guidelines for Indian Public Health Standards for Sub-centers", Directorate General of Health Services, 2006. 